\title{
Competency-based curriculum education in mental health nursing
}

\author{
Jamileh Mohtashami ${ }^{1}$, Mahvash Salsali ${ }^{2}$, Mehrnoosh Pazargadi ${ }^{3}$, Homan Manoochehri ${ }^{3}$, \\ Hamid Alavi Majd ${ }^{4}$ \\ ${ }^{1}$ Psychiatric Nursing Department, Faculty of Nursing \& Midwifery, Shahid Beheshti University of Medical Sciences (International \\ Branch), Tehran, Iran \\ ${ }^{2}$ International Affairs Office, Faculty of Nursing and Midwifery, Tehran University of Medical Sciences, Tehran, Iran \\ ${ }^{3}$ Faculty of Nursing \& Midwifery, Shahid Beheshti University of Medical Sciences, Tehran, Iran \\ ${ }^{4}$ Biostatistics Department, Faculty of Paramedical Sciences, Shahid Beheshti University of Medical Sciences, Tehran, Iran \\ Email: jmohtashami@yahoo.com
}

Received 25 August 2013; revised 26 October 2013; accepted 12 November 2013

Copyright (C) 2013 Jamileh Mohtashami et al. This is an open access article distributed under the Creative Commons Attribution License, which permits unrestricted use, distribution, and reproduction in any medium, provided the original work is properly cited.

\begin{abstract}
Introduction: The essential problems in providing quality and safety services to patients, rapid changes in health care settings as well as information technology require educational revision. Competency-based curriculum focuses on set of skills that students should achieve. This study reviewed characteristics of competency-based curriculum in psychiatric nursing. Methods: A literature review about a competencybased curriculum in psychiatric mental health nursing was carried out by searching databases including Iran Medex, Iran Doc, and Pub Med with key words such as competency-based education, competencybased curriculum, and competency-based curriculum in psychiatric mental health nursing. No time limitation was considered. Results: Results revealed that over 30 literatures have been done about nursing curriculum, but just several studies were done regarding competency-based curriculum and just a few about competency-based curriculum in psychiatric mental health nursing. Conclusion: Competencybased curriculum development is one of the essential steps to facilitate teaching-learning process. The revision of curriculum may decrease theory-practice gap and pave the way for graduates to have essential competences for their roles.
\end{abstract}

Keywords: Curriculum; Competency-Based Education; Mental Health Nursing

\section{INTRODUCTION}

One of the main goals of universities and higher education entities in medical science fields is to create and develop required skills and capabilities in the students and prepare them to offer health services to the society [1]. The purpose of nurse training programs is to train skillful and knowledgeable employees. The training programs are expected to create required skills to carry out clinical services and to ensure development of knowledge bases as the foundation of providing services in complicated clinical situation in the students [2]. A survey of one of the nursing clinical training programs showed that the attained skills by the students are not comparable with the expectations $[3,4]$. The studies on fresh out of college nurses revealed that the students are not ready to undertake their roles as professional nurses. Works on removing anxiety among fresh nurses have been mainly focused on developing required skills and filling the gaps between nursing curriculum and actual situations at work [5].

Some studies have confirmed that there is a direct relation between level of clinical competency and the extent of utilization of the skills in practice [6]. According to the Institute of Medicine (2003), worries about rate of medical errors and safety of patients are increasing; the trend has raised concerns about the gap between clinical needs and competency. Some studies have shown that about $49 \%$ of fresh nurses have made one mistake. They have failed to gain acceptable scores regarding practical and professional merits standards [7]. Reports on serious shortcomings in quality of health services have increased demands for revision in health training curriculums [8]. One study showed that fresh out of college nurses face with several challenges and need help as they do not know what to do in actual situation. Comprehensive supports for the fresh nurses and improving their clinical abilities, skills, and merits meet several clinical chal- 
lenges [9]. World Health Organization (WHO) defines competency as a specific level of performance, which represents utilization of knowledge and effective judgment [6], inter-personal skills, decision making and mastery of doing tasks [3,7]. Competency is a mixture of skills and personal characteristics such as motivation; it is also the main goal of professional training [10]. Competency may be taken as an already known knowledge of how to act in actual clinical situation. Competency is the main factor in performance [11] and triggers a sense of mastery, flexibility, control over clinical situation, and well-planned program to attain merits and organizing [12].

Training plays a key role in development of professional nursing capabilities as it creates opportunities to acquire vast knowledge and capability to solve problem and do critical thinking $[13,14]$. Curriculum programming based on competency focuses on a set of skills that each and every student must master [15]. The goal of competency-based training is to mold students into reliable person to serve the society. That is, university programs must be consistent with needs of society. Nowadays, competency-based education and utilizing the methods as academic courses and other training programs have drawn considerable attention. Researchers have emphasized on ability to work in new, variable, and risky situations $[16,17]$. Forced by the new wave of worries and concerns regarding competency of nurses, some of the nursing programs have stepped toward competency-based curriculum programming. Studies have demonstrated positive effect of such curriculums on increasing competency of the nursing students, accelerating their growth, and attaining more competencies at clinical situation [18]. However, there is paucity of studies on effectiveness of such programs, knowledge regarding content and curriculum of such programs, and the factors in determining differences among graduates of such programs [7]. Competency survey imposes a challenge in nursing work which mirrors challenges and problems of the process. Due to ambiguities or roles of mental health nurses and lack of standards of the services, mental health nursing is a slow growing discipline. American Nurses Association defines psycho-nursing (mental health nursing) as diagnosing and treating human's reaction to potential and actual mental health problems [19]. Some studies have focused on limitations regarding nursing education program and mental health content in particular. These studies have emphasized on negative attitudes of nursing programs in general toward mental health nursing $[20,21]$. From mental health viewpoint, there are worries regarding content of bachelor program of mental health nursing including incompetency of the graduates to provide health care services to the mental patients, which has resulted to shortage of ex- pert nurses. Some of the studies have demonstrated that educational programs have been unsuccessful in preparing the students to provide mental health services [22]. The purpose of the study was to conduct a survey on competency-based education in mental health nursing.

\section{THE CONTENTS OF REVIEW}

Iran Doc, Iran Maddox and American National Library (Pop Med) data banks were searched for the studies pertinent to the specifications of competency-based curriculum for mental health nursing. In doing so, keywords such as competency-based nursing curriculum, mental health nursing competency-based curriculum, and competency-based education were used in the search. Finally, 30 articles on competency-based curriculum programming were found, among them 8 articles were on mental health nursing competency-based curriculum. There was no time limitation in the search.

In spite of the fact that necessity for competent professional nurses has been recognized in nursing literatures since 100 years ago, there have been few measures for programming and implementing development methods. Doubtlessly, faculties of nursing play a pivotal role in development of nursing competencies concerning technical and professional moral values [23]. The purpose of nursing programs is to transfer knowledge and help students to attain required insights for health care services. To have maximum efficiency in theoretical classes, students need to receive required information and develop required skills through practicing and gaining experience in clinical environment [24]. The university is where the effective human force is prepared and supplied to meet the society's needs. To this end, medical sciences universities undertake an important mission toward completion of professional role of the graduates. Concerning education of clinical medical science, acquisition of clinical skills is also taken under consideration along with cognitive goals [25]. The student's knowledge and competencies are based on the knowledge and educations they receive during the program. Curriculum program is an important issue concerning determining the values, goals, and education materials [26]. The curriculum is a wellplanned set of learning opportunities, which is introduced by an organization. Curriculums may differ regarding structure, implementation, and experience [27]. The definition of the concept of competency in medical science field emphasizes on competency-based education along with changes in knowledge, attitudes, and skills of the learners which eventuate in development of capabilities to carry out professional tasks $[9,28]$.

Curriculum planning is commonly known as a challenging process by the faculty members. Necessity to revise the curriculum is undeniable taking into account profound changes in science, complicated health care 
systems, IT, etc. As a part of continuous process of quality improvement, nursing curriculum must be revised in compliance with the changes in clinical situation and evidences based researches [29]. Adopting modern design of curriculums toward effective learning during nursing program seems to be essential taking into account that tradition methods have been proved to ineffective to meet learning needs of bachelor program students. Curriculums must be flexible and provided in different forms depending on clinical environment needs $[27,30]$. Curriculum design includes identifying the main qualifications that the student is supposed to acquire. Implementation of curriculum needs finding approaches for learning/teaching the qualifications required for carrying out an action [31].

What counts in the spectrum of training and assessment by the experts in the field is to prove, maintain, and utilize the knowledge which is directly related with future performance of one. To put in another way, the knowledge and skills are valuable that are directly effective on the professional future and can be used at real situation by the graduate. This is highly critical regarding medical education in particular taking into account the key role of the graduate of the disciplines in public health [32]. Encountered with complicacy of real situation, students find a chance to communicate with the patient and their family, to learn the role model, and to practice what they have learned in theory [33]. A curriculum designed based on competency suits for this type of clinical and educational environment and help the students and the officials to concentrate more on achieving required information and skills through an academic, concentrated and pertinent method [4,5]. This is of great importance for the program to concentrate on development of skills and qualifications in the student [34]. Education plays a key role in development of professional capabilities of the student and gives them the chance to acquire vast knowledge, problem solving skills, and critical thinking techniques [13]. A well-designed curriculum improves critical thinking and leads professional qualifications from simple to more complicated skills [29].

\section{COMPETENCY-BASED CURRICULUM}

It is commonly accepted among the university instructors that academic programs must meet the needs of society. In some cases, there are gaps between knowledge and skill levels. The purpose of competency-based education must be balanced and ensures usefulness of the course and observation of moral codes among the graduates [16]. To this end, there is general trend among other professional health departments and instructors of nursing to design competency-based curriculum. Qualifications are based on academic knowledge, although their develop- ment needs undertaking measures; among them utilization of theoretical content (educational) in actual situation is critical [14]. An important purpose of implementation of qualitative and safe qualifications in nursing program is to bridge the gap between nursing education and clinical situation [28,35]. Determining qualification in designing curriculum may help filling out the gap and prepare the graduates of nursing to combined what is taught and needs to be done at clinical situation [36,37]. To translate this into curriculum language, the outcomes of learning picture the preferred learning process that results in engagement to a specific process or skills which the students must be mastered. There is a close relation between qualifications and outcomes. Qualification in a curriculum might be taken as an important framework for maintaining content of course both for the learner and the faculty. Thus, the content of the program or the elements of the skills can be expressed more clearly [15]. Learning outcomes act as measures for surveying success of university. In addition, the outcome of learning creates opportunity for the graduate to gain the required knowledge and skills. The outcomes are usually referred to as qualifications and skills [17]. Curriculum programing must emphasize strongly on learning and evidences based approaches in clinical works. The approaches is to solve problems of providing health care services which is intentional use of clinical evidences obtained through well-designed studies that integrate clinical expert, values of the patient, and preferences in health care services. Without the best evidences, the practice is soon out of date and induces damages to the patient [38]. The final element of a competency-based approach is to design a set of representation of qualification. By experiencing wide range of learning activities, the student demonstrates their level of skill regarding individuals or a set of qualifications. Moreover, new qualifications are built on previous one and help the student to achieve higher level of skill. For instance, qualification in determining the symptoms entails with psycho-pharmacological interventions can be built on qualifications for surveying and diagnosing. The four elements of competency-based curriculum are merits, pertinent merits, learning activities, and demonstration of the merits [15].

Literature review revealed some points regarding competency-based curriculum. Institute of Medicine (2003) recommended a set of five key qualifications for all the health care staff. This set was later combined by the necessities of bachelor program certificate by the American Association of Colleges of Nursing (AACN) during further revision. The result was a framework for revising the curriculum. The framework is based on a conceptual map diagram that determined the key elements of a nursing bachelor program. At the center are 
the qualifications of the Medical Institute and the nursing process. As the core of the curriculum, nursing process is combined with each one of clinical courses. Surrounding the central elements are four fields that focus on new curriculum: main qualifications, main knowledge, development of professional role and professional values. In addition to revision of the philosophy and mission of nursing school, the framework also follows development of the purposes of students' outcomes and the main values. It is also flexible and can be changed as the situation in future calls [8]. On the other hand, AACN introduced nine necessities of nursing bachelor program including free education for general clinical nursing bachelor, preliminary organizational leadership and systems for quality and safe health care services, evidence-based practical professional literacy, IT utilization and management in health care services, regulations, financial issues, and setting health care environment, inter-personal relation and participation in improvement of health outcomes, clinical prevention, and public health, professionalism and professional values, and graduation in general clinical nursing $[8,29]$.

In 2006, authorities of clinical nursing and education in Massachusetts gathered around to answer how to educate better nurses in the future. During their meeting thirty two experienced nursing education experts and clinical nurses with different viewpoints determined priority of nursing education and practice. Some of them brought in nurse of future (NOF) model, which determines the essential qualifications of nursing education and practice. The centerpiece of the model was nursing knowledge. The ten essential qualifications (patient-oriented health care, professionalism, leadership, systematic work, IT, communication, teamwork and participation, safety, quality improvement, and evidence-based process) as guideline of nursing education and practice were rooted in the central elements of the model [39].

\section{COMPETENCY-BASED CURRICULUM IN MENTAL HEALTH NURSING}

There are few studies on clinical qualifications of mental health nursing [40]. Likewise any field of health services, the nature of mental health nursing has undergone considerable changes in the West. The changes-change in population of health care seekers, case management, health care services (e.g. from hospital to society) and health care patterns-have influenced mental health care practices. Furthermore, the changes have extended to provision of education for mental health nurses, recruitment, job opportunities and development of practical work [41]. Mental health nurse is defined as qualified staff with required knowledge, skill, and capabilities to provide health care services to mental health patients with mental disorders. Qualification is obtained through both education and experience [42]. The main emphasis on mental health service is to improve and preserve mental health performance, prevention of mental diseases, and to help the referrals to recover their health. These goals are realized through a wide range of nursing activities at different wards of hospital or sections of society $[14,43]$.

Mental health nursing is faced with increasing challenges. Along with development of mental health knowledge, pertinent technology expands into new aspects, which means clinical works of nurse is becoming more independent and professionalized. Nowadays, the challenge ahead of mental health nurses is to keep their knowledge updated and provide safe and quality health care to mental disorder patients [42]. Aging population, cultural differences, and developing technology are among the factors that influence future of mental health nursing [43].

It is frequently stated that there are shortcomings in the comprehensive nursing programs in theoretical and clinical education regarding health care provided to mental patients. Studies have shown that such shortcomings have made the graduate incompetent to take their role as mental health care provider [4,20,21]. Worries regarding lack of professional development among the nurses and mental health nurses in particular, may influence health care standards [22]. Melnyk et al. at Yale University showed that about half of the authorities believed that recent graduates are not able to provide health services to the families seeking help. The required skills in the field of mental/behavioral health care services cover a wide range and the curriculum has failed to take into account the screening tools and evidence-based preliminary interventions [38]. Moreover, increasing worries are expressed regarding incompetency of mental health nurses regarding drugs management; although in some countries nurses are not permitted to prescribe medicine [44]. According to the studies, small numbers of nursing students tend to enter in mental health nursing field and prefer other fields such as children and internal wards. It is believed that reluctance to enter mental health profession among the nursing students is due to lack of enough field experience in mental health nursing during the education program. In addition, the graduates are not prepared to work in mental health ward $[20,45]$.

There are several unique fields in competency-based curriculum. By finding the competencies throughout the program, the students have the chance of experience the competencies. In addition assessment measures are developed throughout the course. Complicated competencies are required for mental health services provision. Members of faculty board encounter with variety of clinical experience in different situations while working with students from different majors. For instance, some 
students enter mental health program with years of experience in the field, while some have no relevant experience. Under competency-based program, different groups of students are expected equal qualifications to word under different clinical situations. Members of faculty board recognize that students follow different paths to gain the qualifications. Thus, necessarily the program must fit individual experience of each student and be flexible. Competency-based learning requires the student to develop a habit of curiosity, attention, self-awareness, reflection, and self-correction [14].

There are also few studied in other countries on competency-based curriculum programming in mental health nursing. Happell (2010) named six fields of mental health nursing based on the report by National Review of Nursing Education including forensic/moral and physical treatments, current classification of diseases, patientnurse relation, and individual/public mental health [20]. Moreover, a framework of learning/teaching content of curriculum programming before professional work was recommended by mental health nursing education taskforce (MHNET), including: principle values to learn about learning/teaching process, outcomes of mental health learning content, principles of learning and teaching mental health content, and criteria to determine mental health content indices.

MHNET also made recommendations to spot the executive obstacles toward revising the curriculum such as designing principle and fundamental values of learningteaching process of mental health nursing, involving student in the education, strengthening universities and health centers [22].

Klein and Fowles studied the effect of a competencybased curriculum model on competency based on COPA model for acquisition of clinical competency by the student. They found that student-centered strategy, which constitutes an important part of the model, exerts considerable effect on acquisition of the six sub-scales by the students [7]. Delaney et al. (2010) named the specifications of competency-based education: clearly defines the competencies, defines specialized competencies within daily clinical tasks, creates required skills for acquisition of clinical competencies, leaves experiencing to the student, improves learning abilities toward self-assessment, determines existing gaps in clinical experiences and learning needs of the students, and sets the competency learning based on the experience and background of students.

\section{BACKGROUND IN IRAN}

There is no study on competency-based curriculum in mental health fields in Iran. However, taking into account educational experiences of recent 20 years of authors in mental health nursing and the results the qualita- tive study (not published yet), there are shortcomings in the current curriculum, which may result in failure of students to acquire required skills and qualification by a mental health nurse. Some of the shortcomings are inadequacy of theory course, the gap between individual and social psychology course (dealing with the basic concepts of perception and knowledge mental disorder patients) and the courses mental health (1) and (2), short and irrelevant mental health training courses (students almost forget what they have learned in previous course and have to waste their time reviewing the old materials) uncovered issues during the program such as sleep disorders, eating disorders, impulsive and factitious disorders, child and adolescent psychiatry, health care for special cases, legal and moral issues in mental health nursing, introduction to professional identity and values of psychiatric nursing, how to deal with stigmatization and negative attitudes regarding mental patients, and so on. Furthermore, apparently the courses such as psychopharmacology and bio-bases of behavior must be integrated in the courses to enable the student perceive psychological disorders. Taking into consideration new advents in genetics and immunology regarding mental disorders, these findings must be added to the courses. Necessity of mental disorders screening tools in mental health course is undeniable. Moreover, the students must be able to use the findings of researches in mental health field.

In general, rather than the way of proving health care and communication with the patient, current mental health nursing program emphasizes on psychological disorders. After graduation, the student is not able to communicate with the patients in mental ward and even to put into practice what they have learned in theory. Apparently, modification of mental health nursing curriculum such as adopting more practical concepts, emphasizing on communication and communication therapy, adopting new education methods with better learning performance, surveying students values and attitudes regarding mental health nursing are essential to ensure that students are prepared to help mental patient in clinical situation.

\section{CONCLUSION}

Taking the literature into consideration, new curriculum design is aimed to facilitate learning/teaching process-a necessity of any education system. Revision of curriculum may fill in the gap between theory and practice, and ensure that the graduates are equipped with required qualifications to play their role in practice.

\section{ACKNOWLEDGEMENTS}

The present article is part of a $\mathrm{PhD}$ thesis proposed and conducted in 
International Branch, Shahid Beheshti Medical Science University. The author express their gratitude toward the officials of the university and faculty of nursing and midwifery, the professors and instructor of psycho-nursing, head nurses, the nurses working in psychology wards, and the students who without their contribution it was not possible to conduct the study.

\section{REFERENCES}

[1] Amini, A., Hasanzadeh Salmasi, S., Shaghaghi, A., Safaei, N. and Sedaghat, K. (2005) Effect of clinical skills training necessary in labour on medicine student's clinical competency of Tabriz Medical University. Iranian Journal of Education in Medical Sciences, 5, 8-12.

[2] Gidman, J., McIntosh, A., Melling, K. and Smith, D. (2011) Student perceptions of support in practice. Nurse Education in Practice, 11, 351-355. http://dx.doi.org/10.1016/j.nepr.2011.03.005

[3] Parsa Yekta, Z., RamezaniBadr, F. and Khatoni, A. (2006) Nursing students' views about clinical competency and achievement rate. Iranian Journal of Nursing Research, 1, 7-14.

[4] Farrand, P., McMullan, M., Jowett, R. and Humphreys, A. (2006) Implementing competency recommendations into pre-registration nursing curricula: Effects upon levels of confidence in clinical skills. Nurse Education Today, 2, 97-103. http://dx.doi.org/10.1016/j.nedt.2005.06.002

[5] Heshmati Nabavi F. and Vanaki, Z. (2009) Effective clinical instructor: A qualitative study. Iranian Journal of Nursing Research, 4, 39-53.

[6] Bahreini, M., Moattari, M., Akaberian, Sh. and Mirzaei, K. (2008) Determining nurses' clinical competence in hospitals of Bushehr University of Medical Sciences by self assessment method. Iranian South Medical Journal, 11, 69-75.

[7] Klein, C.Y. and Fowles, E.R. (2009) An investigation of nursing competence and the competency outcomes performance association curricular approach: Senior students' self-reported perceptions. Journal of Professional Nursing, 25, 109-121.

http://dx.doi.org/10.1016/j.profnurs.2008.08.006

[8] Hickley, M.T., Forbes, M. and Greenfield, S. (2010) Integrating the institute of medicine competencies in a baccalaureate curricular revision: Process and strategies. Journal of Professional Nursing, 26, 241-222.

[9] Jaffari Golestan, N., Vanaki, Z. and Memarian, R. (2004) Organizing "Nursing Mentors Committee": An effective strategy for improving novice nurses' clinical competency. Iranian Journal of Education in Medical Sciences, 7, 237-247.

[10] Applin, H., Williams, B., Day, R. and Buro, K. (2011) A comparison of competencies between problem-based learning and non-problem-based graduate nurses. Nurse Education Today, 31, 129-134.

http://dx.doi.org/10.1016/j.nedt.2010.05.003

[11] Stobinski, J. (2008) Preoperative nursing competency. AOPN Journal, 88, 417-436.
[12] Johnsin, B.M. and Webber, P.B. (2010) An Introduction to theory and reasoning in nursing. 3rd Edition, Lippincott Williams \& Wilkins, Philadelphia,.

[13] Dias, J.M., Ajani, K. and Mihtani, Y. (2010) Conceptualization and operationalization of a baccalaureate nursing curriculum in Pakistan: Challenges; hurdles and lessons learnt. Procedia Social and Behavioral Sciences, 2, 2335-2337. http://dx.doi.org/10.1016/j.sbspro.2010.03.332

[14] Delaney, K., Calrson-Sabelli, L., Shephard, R. and Ridge, A. (2010) Competency-based training to create the $21^{\text {st }}$ century mental health workforce: Strides, stumbles and solutions. Archives of Psychiatric Nursing, 25, 225-234. http://dx.doi.org/10.1016/j.apnu.2010.09.003

[15] LeCuyer, E., DeSocio, J., Brody, M., Schlick, R. and Menkens, R. (2009) From objectives to competencies: Operationalizing the NONPF PMHNP competencies for use in a graduate curriculum. Archives of Psychiatric Nursing, 23, 185-199. http://dx.doi.org/10.1016/j.apnu.2008.06.004

[16] Mojab, F., Zaefarian, R. and Dazian Azizi, A.H. (2011) Applying competency based approach for entrepreneurship education. Procedia Social and Behavioral Sciences, 12, 436-447. http://dx.doi.org/10.1016/j.sbspro.2011.02.054

[17] Hsieh, S.I. and Hsu, L.L. (2013) An outcome-based evaluation of nursing competency of baccalaureate senior nursing students in Taiwan. Nurse Education Today, 33, 1536-1545. http://dx.doi.org/10.1016/j.nedt.2013.01.012

[18] Yanhua, C. and Watson, R. (2011) A review of clinical competence assessment in nursing. Nurse Education Today, 31, 832-836. http://dx.doi.org/10.1016/j.nedt.2011.05.003

[19] Mohtashami, J. and Noughani, F. (2011) Psychiatric nursing. Teimoorzadeh Co, Tehran.

[20] Happell, B. (2010) Moving in circles: A brief history of reports and inquiries relating to mental health content in undergraduate nursing curricula. Nurse Education Today, 30, 643-648. http://dx.doi.org/10.1016/j.nedt.2009.12.018

[21] Happell, B. and Platania-Phung, C. (2005) Mental health issues within the general health care system: The challenge for nursing education in Australia. Nurse Education Today, 25, 465-471. http://dx.doi.org/10.1016/j.nedt.2005.04.005

[22] MacCann, T.V., Moxham, L., Farrell, G., Usher, K. and Crookes, P. (2010) Mental health content of Australian pre-registration nursing curricula: Summary report and critical commentary. Nurse Education Today, 30, 393397. http://dx.doi.org/10.1016/j.nedt.2009.08.002

[23] Borhani, F., Alhani, F., Mohammadi, E. and Abasszadeh, A. (2009) Development of professional ethics competency of nurses, essentials and challenges in ethics education. Ethics and History of Medicine Journal, 2, 27-38.

[24] Sabeti, F., Akbari-Nassaji, N. and Haghighy Zadeh, M.H. (2011) Nursing students' self-assessment regarding clinical skills achievement in Ahvaz Jundishapur University of Medical Sciences. Iranian Journal of Education in Medical Sciences, 11, 506-515. 
[25] Mohammadi, F. and Hosseini, M.A. (2010) Rehabilitation sciences students' perception from clinical self-efficacy compared to evaluation by clinical teachers. Iranian Journal of Education in Medical Sciences, 10, 155-163.

[26] Najafi Kalyani, M., Sharif, F., Jamshidi, N. and Karimi, S.H. (2010) Students' perceptions of effective teaching in nursing education: A qualitative study. Iranian Journal of Nursing Research, 5, 6-19.

[27] Hall, C. (2013) Toward a model of curriculum analysis and evaluation-Beka: A case study from Australia. Nurse Education Today. http://dx.doi.org/10.1016/j.nedt.2013.04.007

[28] Hsu, L.L. and Hsieh, S.I. (2013) Development and psychometric evaluation of the competency inventory for nursing students: A learning outcome perspective. Nurse Education Today, 33, 492-497. http://dx.doi.org/10.1016/j.nedt.2012.05.028

[29] Mailloux, C.G. (2011) Using the essentials of baccalaureate education for professional nursing practice (2008) as a framework for curriculum revision. Journal of Professional Nursing, 27, 385-389. http://dx.doi.org/10.1016/j.profnurs.2011.04.009

[30] Fitzgerald, L., Wong, P., Hannon, J., Solberg Tokerud, M. and Lyons, J. (2013) Curriculum learning designs: Teaching health assessment skills for advanced nursing practitioners through sustainable flexible learning. Nurse Education Today, 33, 1230-1236. http://dx.doi.org/10.1016/j.nedt.2012.05.029

[31] Lee, R.L.T., Wong, T.K.S., Al-Gaseer, N., Wu, C.S.T., Chan, S.S.S., Co, S.K.K. and Chan, T.M.F. (2006) Evaluating the efficacy of an integrated curriculum on adolescent health and development for pre-service nursing education in Hong Kong. Nurse Education Today, 26, 286297. http://dx.doi.org/10.1016/j.nedt.2005.10.008

[32] Shayan, S.H. (2010) Using Patient Management Problem (EPMP) in assessment of clinical competency. Iranian Journal of Education in Medical Sciences, 10, 10871092.

[33] Levett-Jones, T. and Lathlean, J. (2008) Belongingness: A prerequisite for nursing students' clinical learning. Nurse Education in Practice, 8, 103-111. http://dx.doi.org/10.1016/j.nepr.2007.04.003

[34] Memarian, R., Salsali, M., Vanaki, Z., Ahmadi, F. and Hajizadeh, E. (2007) Professional ethics as an important factor in clinical competency in nursing. Nursing Ethics, 14, 203-214. http://dx.doi.org/10.1177/0969733007073715

[35] Mulready-Shick, J., Kafel, K.W., Banister, G. and Mylott,
L. (2009) Enhancing quality and safety competency development at the unit level: An initial evaluation of student learning and clinical teaching on dedicated education units. Journal of Nursing Education, 48, 716-719. http://dx.doi.org/10.3928/01484834-20091113-11

[36] Staykova, M.P. (2012) A pilot delphi study: Competencies of nurse education in curriculum design. Teaching and Learning in Nursing, 7, 113-117. http://dx.doi.org/10.1016/j.teln.2012.01.006

[37] De Gagne, J.C., Bisanar, W.A., Makowski, J.T. and Neumann, J.A. (2012) Integrating informatics into the BSN curriculum: A review of the literature. Nurse Education Today, 32, 675-682. http://dx.doi.org/10.1016/j.nedt.2011.09.003

[38] Melnyk, B.M., Hawkins-Walsh, E., Beauchesne, M., Brandt, P., Crowley, A., Choi, M. and Greenburg, E. (2010) Strengthening PNP curricula in mental/behavioral health and evidence-based practice. Journal of Pediatric Health Care, 24, 81-94. http://dx.doi.org/10.1016/j.pedhc.2009.01.004

[39] Sroczynski, M., Gravlin, G., Sroute, P., Hoffart, N. and Creelman, P. (2011) Creativity and connections: The future of nursing education and practice: The Massachusetts initiative. Journal of Professional Nursing, 27, e64-e70. http://dx.doi.org/10.1016/j.profnurs.2011.08.007

[40] Gilje, F.L., Klose, P.M.E. and Birger, J. (2006) Critical clinical competencies in undergraduate psychiatric mental health nursing. Journal of Nursing Education, 46, 522526.

[41] Gass, J., McKie, A., Smith, I., Brown, A. and Addo, M. (2007) An examination of the scope and purpose of education in mental health nursing. Nurse Education Today, 27, 588-596. http://dx.doi.org/10.1016/j.nedt.2006.08.020

[42] Boyd, M.A. (2012) Psychiatric nursing, contemporary practice. $5^{\text {th }}$ Edition, Wolters Kluwer/Lippincott Williams \& Wilkins, Philadelphia.

[43] Varcarolis, E.M., Carson, V.B. and Shoemaker, N.C. (2006) Foundations of psychiatric mental health nursing, a clinical approach. 5th Edition, Saunders.

[44] Snowden, A. (2010) Integrating medicines management into mental health nursing in UK. Archives of Psychiatric Nursing, 24, 178-188. http://dx.doi.org/10.1016/j.apnu.2009.12.003

[45] Hoekstra, H.J., Bvan Meijel, B. and van der Hooft-Leemans, T.G. (2010) A nursing career in mental health care: Choices and motives of nursing students. Nurse Education Today, 30, 4-8. http://dx.doi.org/10.1016/j.nedt.2009.05.018 